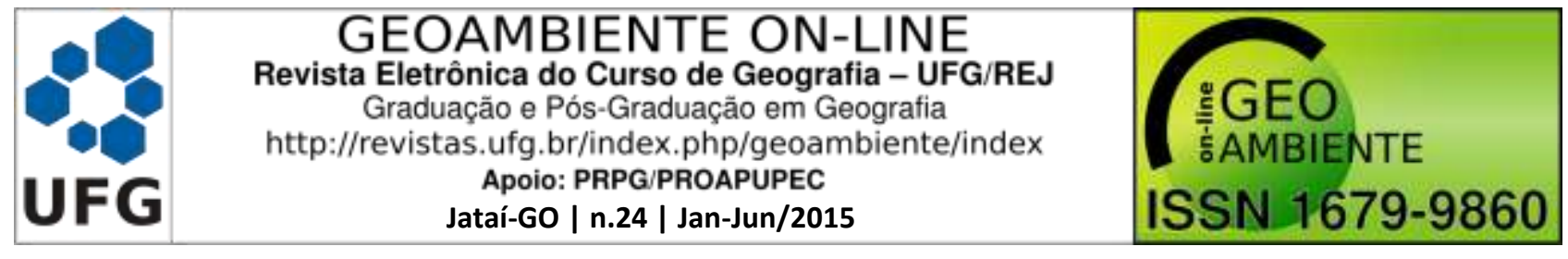

\title{
A RELAÇÃO ENTRE PESSOAS, PAISAGEM E GEOSSÍMBOLOS NA COMUNIDADE RURAL LINHA CRICIUMAL, CÂNDIDO DE ABREU -
} PR

\author{
Juliano Strachulski ${ }^{1}$
}

(1- Universidade Estadual de Ponta Grossa - UEPG, Doutorando em Geografia pela UEPG, julianomundogeo@gmail.com. Av. G.al Carlos Cavalcanti, 4748, CEP: 84030-900, Ponta Grossa/PR)

Resumo: Este trabalho teve como objetivo compreender a relação entre as pessoas, a paisagem e os geossímbolos na comunidade rural Linha Criciumal em Cândido de Abreu PR. Para tanto, foi utilizado como referencial teórico o conceito de paisagem, que está compreendida como marca das ações humanas e matriz que contempla e revela os aspectos culturais importantes de uma sociedade, representada por seus geossímbolos, que lhes dão sentido e significado. Por sua vez, estes elementos materializados ressaltam as vivências e narrativas das pessoas, ajudando a compreender a relação entre estas e suas paisagens. A metodologia utilizada contou com a realização da técnica da observação participante e de entrevistas informais. Como resultados, foram identificados diversos geossímbolos que retratam as várias faces desta sociedade, como o trabalho agrícola e o lazer, representados por instrumentos, construções e elementos do meio físico, além das superstições, crenças e religiosidade, que retratam seu imaginário e o quanto este interfere em suas vidas, reforçando a ligação entre as pessoas e a paisagem. Assim, os geossímbolos locais expressam as crenças e vivências das pessoas em relação à sua paisagem. Por fim, destaca-se a importância de se compreender a relação dos geossímbolos com as paisagens, pois, possibilitam captar a essência do vínculo das pessoas com o meio local.

Palavras-chave:Geossímbolos; paisagem; comunidade Linha Criciumal.

\section{THE RELATIONSHIP BETWEEN PEOPLES, LANDSCAPE AND GEOSYMBOLOS IN RURAL COMMUNITY LINHA CRICIUMAL, CÂNDIDO DE ABREU - PR}

Abstract: This study aimed to understand the relationship between people, the landscape and geosymbols in the rural community Linha Criciumal in Cândido de Abreu - PR. Thus, it was used as a 


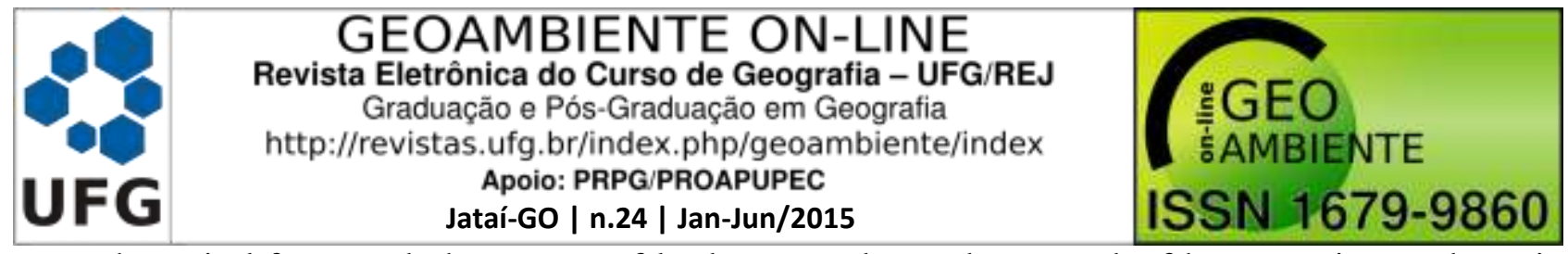

theoretical framework the concept of landscape, understood as a mark of human actions and matrix that contemplates and reveals important cultural aspects of a society, represented by geosymbols that give them meaning and significance. In turn, these elements materialized highlighting the experiences and narratives of people, help to understand the relationship between these and its landscapes. The methodology used included the applying of participant observation technique and informal interviews. As a result, several geosymbols were identified, that portray the many faces of this society, such as agricultural work and the leisure, represented by instruments, buildings and elements of the physical environment, in addition to superstitions, beliefs and religiosity, that depict its imaginary and how this interfere in their lives, strengthing the link between people and landscape. Thus, the local geosymbols express the beliefs and experiences of people in relation to their landscape. Finally, there is the importance of understanding the relationship of geosymbols with the landscapes, therefore, making possible the capture of essence of the relationship between people and local environment.

Keywords: Geosymbols; landscape; community Linha Criciumal.

\section{LA RELACIÓN ENTRE LAS PERSONAS, EL PAISAJE Y LOS GEOSSÍMBOLOS EN LA COMUNIDAD RURAL LINHA CRICIUMAL, CÂNDIDO DE ABREU - PR}

Resumen: Este estudio tuvo como objetivo comprender la relación entre las personas, el paisaje y los geossímbolos de la comunidad rural Linha Criciumal en Cândido de Abreu - PR. Por lo tanto, se utilizó el referencial teórico del concepto de paisaje. Por lo tanto, se utilizó como marco teórico el concepto de paisaje, que se entiende como una marca de las acciones humanas y matriz que contempla y revela aspectos culturales importantes de una sociedad, representada por geossímbolos que le dan sentido y significado. A su vez, estos elementos materializado subrayan las vivencias y narrativas de las personas, ayudando a entender la relación entre éstos y sus paisajes. La metodología utilizada incluyó la realización de la técnica de la observación participante y las entrevistas informales.Como resultado, se identificaron varios geossímbolos que retratan las múltiples facetas de esta sociedad, como el trabajo agrícola y el ocio, representados por instrumentos, construcciones y elementos del medio físico, además de supersticiones, creencias y religiosidad, que representan su imaginario y cómo esto interfiere en sus vidas, fortaleciendo el vínculo entre las personas y el paisaje. Así, los geossímbolos locales expresan las creencias y experiencias de las personas en relación a su paisaje. Por último, se desta la importancia de comprender la relación de los geossímbolos con las paisajes, pues, permiten captar la esencia de la relación entre las personas y el entorno local. 


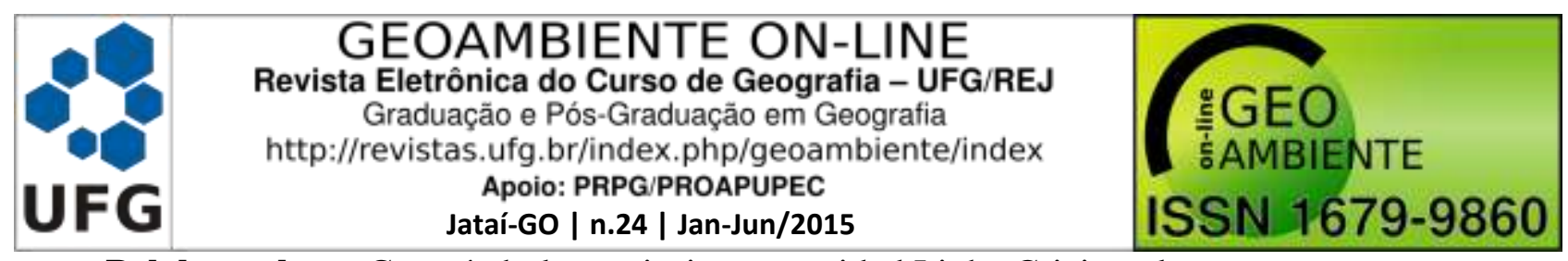

Palabras clave: Geossímbolos; paisaje; comunidad Linha Criciumal.

\section{Introdução}

$\mathrm{Na}$ percepção de uma paisagem são considerados determinados elementos com expressivos significados para os habitantes locais, trata-se de símbolos com extensão cultural, segundo Bonnemaison (2002) os "geossímbolos". Estes elementos culturalmente reproduzidos por uma coletividade ressaltam a visão de mundo dos grupos humanos, ganhando força e destaque por sua materialidade na superfície terrestre.

Os geossímbolos dão significado às paisagens, representando experiências, narrativas, valores e sentimentos das pessoas que nelas viveram ou ainda vivem, de forma a caracterizar determinada porção desta paisagem (BONNEMAISON, 2002). Eles representam a história coletiva ou individual das pessoas de uma comunidade com suas paisagens. Nesses termos, atribuem valores, selecionam elementos, simplificam e dão sentido à realidade vivida.

No meio rural isto é mais notadamente verificado, pois muitas crenças e características culturais tradicionais são preservadas na forma de geossímbolos, como trajetos religiosos, construções e instrumentos de trabalho. Tais elementos guardam a vivência cotidiana e as lembranças em forma de um sistema de memória coletiva que fundamenta a relação do grupo com sua paisagem.

Neste sentido, a paisagem representada por seus geossímbolos pode ser compreendida como sendo marca de ações de grupos humanos e matriz que contempla e exprime aspectos culturais relevantes da sociedade (BERQUE, 1998). Ela revela características próprias de determinada cultura (comunidade) seus valores, e perspectivas futuras, que assentados sobre os geossímbolos ajudam a compreender sua relação com as pessoas.

A relação criada entre pessoas e paisagem é intermediada e ressaltada pelos geossímbolos, de modo que a essência desta pode ser captada por meio de sua percepção e representação. Desta forma, revela as singularidades da tríade a qual faz parte: paisagempessoas-geossímbolos.

$\mathrm{Na}$ comunidade Linha Criciumal foram identificados vários geossímbolos que representam elementos da cultura local, como o trabalho, lazer, superstição, crenças e religiosidade, e que reforçam a ligação das pessoas com a paisagem.

Estes ícones retratam também sua própria ligação com a paisagem, pois são representados e significados por uma visão de mundo construída por uma vivência que os 


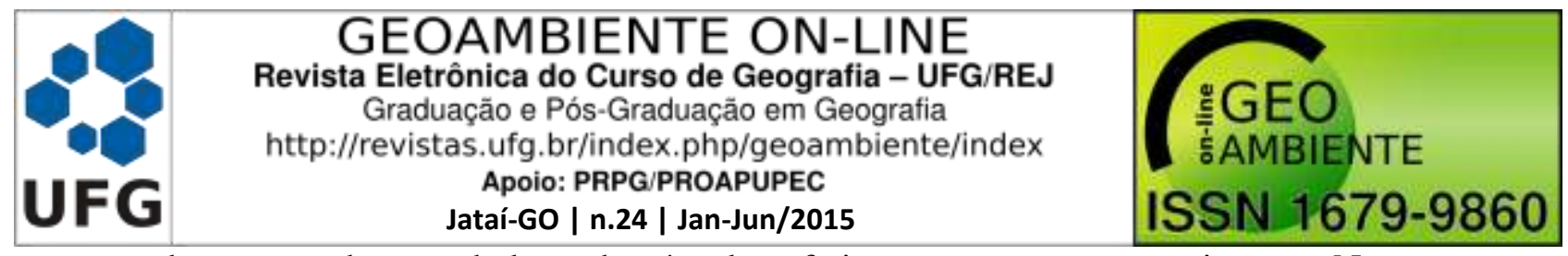

produz e reproduz, estabelecendo vínculos afetivos entre pessoas e paisagem. Nestes termos, buscou-se compreender a relação entre pessoas, paisagem e geossímbolos da comunidade rural Linha Criciumal em Cândido de Abreu-PR.

\section{Metodologia}

A pesquisa realizada foi de natureza qualitativa, compreendida enquanto um estudo de caso, contando primeiramente com uma revisão de literatura acerca do conceito de geossímbolo e sua relação com a paisagem.

Por outro lado, também contou com a realização de trabalhos de campo na comunidade Linha Criciumal, dentre os anos de 2012 e 2013, com estadias aproximadas de uma semana cada.

Os trabalhos de campo possibilitaram perceber os processos em curso na comunidade, cujo principal objetivo foi compreender a relação entre geossímbolos, pessoas e paisagem local.

De início, buscou-se uma aproximação com os moradores, extraindo informações gerais a partir de conversas informais. Num segundo momento, foram realizadas observações in loco e em seguida se fez uso da observação participante (GIL, 2008). Esta técnica permitiu uma maior aproximação com os membros da comunidade, buscando através do convívio cotidiano com estes captar sua vivência na paisagem.

Desta maneira, foi possível participar das atividades rotineiras do trabalho agrícola. Como exemplo, destaca-se a colheita do feijão, além de eventos religiosos como procissões e visitas da "santinha" (capelinha), além de ocasiões de sociabilidade (festas e visitas as casas), permitindo compreender a relação entre pessoas, geossímbolos e a paisagem.

Assim, foram realizadas várias conversas, denominadas de entrevistas informais (GIL, 2008), possibilitando uma visão geral acerca do problema de pesquisa, sendo acompanhadas de registros fotográficos, demonstrando o campo de estudo e a presença dos geossímbolos na paisagem.

\section{O conceito de geossímbolo e sua relação com a paisagem}

Os símbolos culturalmente reproduzidos em uma coletividade ressaltam a visão de mundo dos grupos humanos e ganham maior força e destaque quando personificam em lugares. Assim, quando os símbolos se materializam, por exemplo, em uma paisagem se 


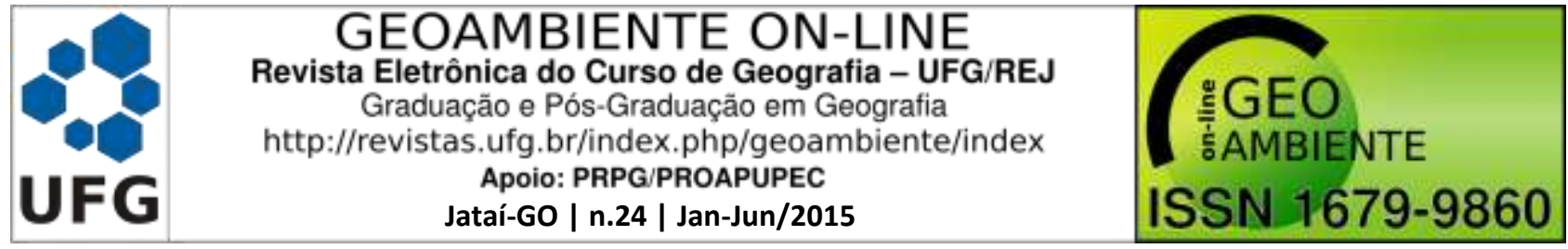

transformam em símbolos geográficos ou mais comumente: geossímbolos.

Estes elementos, por sua vez, dão significado às paisagens, representando vivências, narrativas, valores e sentimentos das pessoas (Figura 1) que nelas viveram ou ainda vivem, de forma a caracterizá-la (BONNEMAISON, 2002). Eles representam a história coletiva ou individual das pessoas de uma comunidade com suas paisagens. Nesses termos, atribuem valores, selecionam informações, simplificam e dão sentido à realidade vivida.

Figura 1 - Croqui mostrando a relação entre pessoas, paisagem e geossímbolos



Fonte: $\mathrm{O}$ autor.

Org.: O autor, 2015.

Os geossímbolos de uma paisagem representam referências para a memória de vários grupos humanos, pois reforçam as relações sociais e a identidade local, fortalecendo as representações do cotidiano (paisagem vivida). Assim, a cada momento vivido ajudam a reavivar a ligação dos indivíduos com a paisagem que os envolve.

Meinig (1979) assevera que o simples ato de observar a paisagem nos permite múltiplos significados acerca desta. Contudo, o ato de olhar só traz significados e não revela sentimentos, que são construídos ao longo do tempo e intensificados a partir da vivência na paisagem local.

A sinergia que existe entre os grupos humanos e suas paisagens é exposta pelos geossímbolos, que materializam sentimentos e percepções que por si só não conseguem expressar a importância de uma e outra conotação. Para Bonneimason (2002, p. 123) os geossímbolos de uma paisagem são "a verificação terrestre de mitos, a fonte de poderes cósmicos e os fundamentos da organização social".

Por outro lado, permitem compreender a interação existente entre os seres humanos e suas paisagens, possibilitando a interpretação destas. Nestes termos, refletem sua estrutura, onde as representações e os modelos são distintamente vivenciados e valorizados, se 




constituindo no fruto de suas várias atualizações, formando estilos culturais (ELIADE, 1991).

Já para Rosendahl (2007, p. 214) “a paisagem é uma estrutura visível, na qual a mensagem que nela se escreve em termos geossimbólicos reflete o peso do sonho, das crenças dos homens e de sua busca de significação."

Portanto, "os geossímbolos vão além da cultura, pois dizem respeito à concepção que essa coletividade enraizada em seu território faz do mundo e de seus próprios destinos, numa realidade muito mais sonhada do que vivida" (SILVA; TULUX; LE BOURLEGAT, 2011, p. 22).

Os geossímbolos abarcam um conjunto de atributos que estruturam a paisagem por meio de sua dimensão simbólica. Para Bonnemaison (2002, p.109) "um geossímbolo pode ser definido como um lugar, um itinerário, uma extensão que, por razões políticas, religiosas ou culturais, aos olhos de certas pessoas e grupos étnicos assume uma dimensão simbólica que os fortalece em sua identidade".

Neste sentido, o geossímbolo ocorre em um determinado espaço de forma simbólicocultural, possibilitando identificar e ressaltar a identidade de uma comunidade em relação a uma determinada paisagem (CORRÊA, 2007). Desta forma, as paisagens "apresentam geossímbolos, fixos, que, por serem dotados de significados identitários, fortalecem a identidade cultural dos grupos que as habitam" (CORREA, 2008, p. 12).

O referido conceito permite "aprofundar o papel do simbólico no espaço e supõe que os símbolos adquirem mais força e destaque quando encarnam ou se fixam em lugares e paisagens específicas" (GIMÉNEZ; LAMBERT, 2007, p. 17).

Contudo, para Tuan (1974, p. 200 apud DELGADO, 2005, p. 67-68), “a razão dos geossímbolos não é algum atributo físico intrínseco, mas a sua eficácia, articulando e simbolizando os verdadeiros sentimentos históricos de uma comunidade ou de uma parte da comunidade". Desta forma, se torna parte da dinâmica histórica e em continua transformação da paisagem.

A compreensão do que seja um geossímbolo permite dizer que as marcas deixadas pelos grupos e os artefatos existentes em qualquer paisagem podem ser consideradas como geossímbolos. Segundo Bonnemaison (2002, p. 124) o lócus de sua existência é "uma forma de linguagem, um instrumento de comunicação partilhado por todos e, em definitivo, o lugar onde se inscreve o conjunto da visão cultural”.

As paisagens, assim, apresentam atrativos que prendem a atenção daqueles que as 


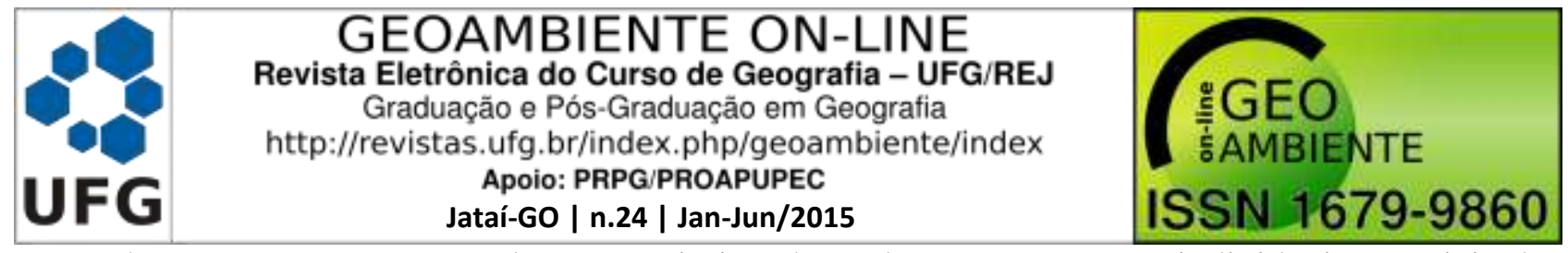

observam, uma vez que ela se constitui na base das representações individuais e sociais dos indivíduos e grupos de indivíduos que constantemente as transformam.

Portanto, lugares ricos em valores simbólicos podem ser considerados geossímbolos: "representados por pontos fixos, como construções, caminhos, formas do relevo, rios, árvores, estradas, e itinerários reconhecidos, traçando na superfície uma semiografia engendrada por símbolos, figuras e sistemas espaciais”(BONNEMAISON, 2002, p. 105).

Doutra forma, representam a história coletiva de um povo com suas paisagens, pois, "mantêm em sua estrutura elementos de uma tradição iniciadas pelos seus antepassados" (TEIXEIRA, 2009, p. 131).

$\mathrm{Na}$ concepção de Bonnemaison (2002), qualquer elemento pode se tornar geossímbolo, desde que para uma determinada comunidade ou grupo de pessoas possua algum significado, uma representação ligada a sua vivência em uma determinada paisagem. Pois, "todas as paisagens possuem significados simbólicos porque são o produto da apropriação e transformação do meio ambiente pelo homem” (COSGROVE, 1998, p. 108).

Desta forma, compreende-se que por meio dos geossímbolos é que as ações dos indivíduos de uma determinada sociedade registram suas marcas culturais que acabam por identificar e singularizar suas paisagens em relação às demais.

Portanto, a paisagem deve ser pensada como elemento transformado e transformadorcondicionador, sendo marca de ações de grupos humanos e matriz que contempla e exprime aspectos culturais relevantes da sociedade (BERQUE, 1998). Nestes termos, revela características próprias de determinada cultura, seus valores e perspectivas futuras, impressas nos geossímbolos que dão expressividade aos sentidos contidos nas paisagens.

Os geossímbolos, assim, além de atrativos, guardam os significados das paisagens, representando as práticas (sociais e produtivas) de uma determinada comunidade ou grupo social. Tais geossímbolos definem, de acordo com Rua (2005, p. 55), "a inscrição da cultura de um grupo sobre seu espaço, enquanto produto de apropriação e valorização simbólica (afetiva)".

\section{Os geossímbolos da paisagem da comunidade Linha Criciumal}

A comunidade rural Linha Criciumal possui área de 1.222 ha (Figura 2), tendo sua origem a partir do processo de colonização do estado do Paraná, possuindo mais de 100 anos 
de existência. Sua localização é o sul no município de Cândido de Abreu, estando há aproximadamente $50 \mathrm{~km}$ da área urbana deste.

Figura 2 - Mapa de localização da área de estudo, com a delimitação feita pelos moradores

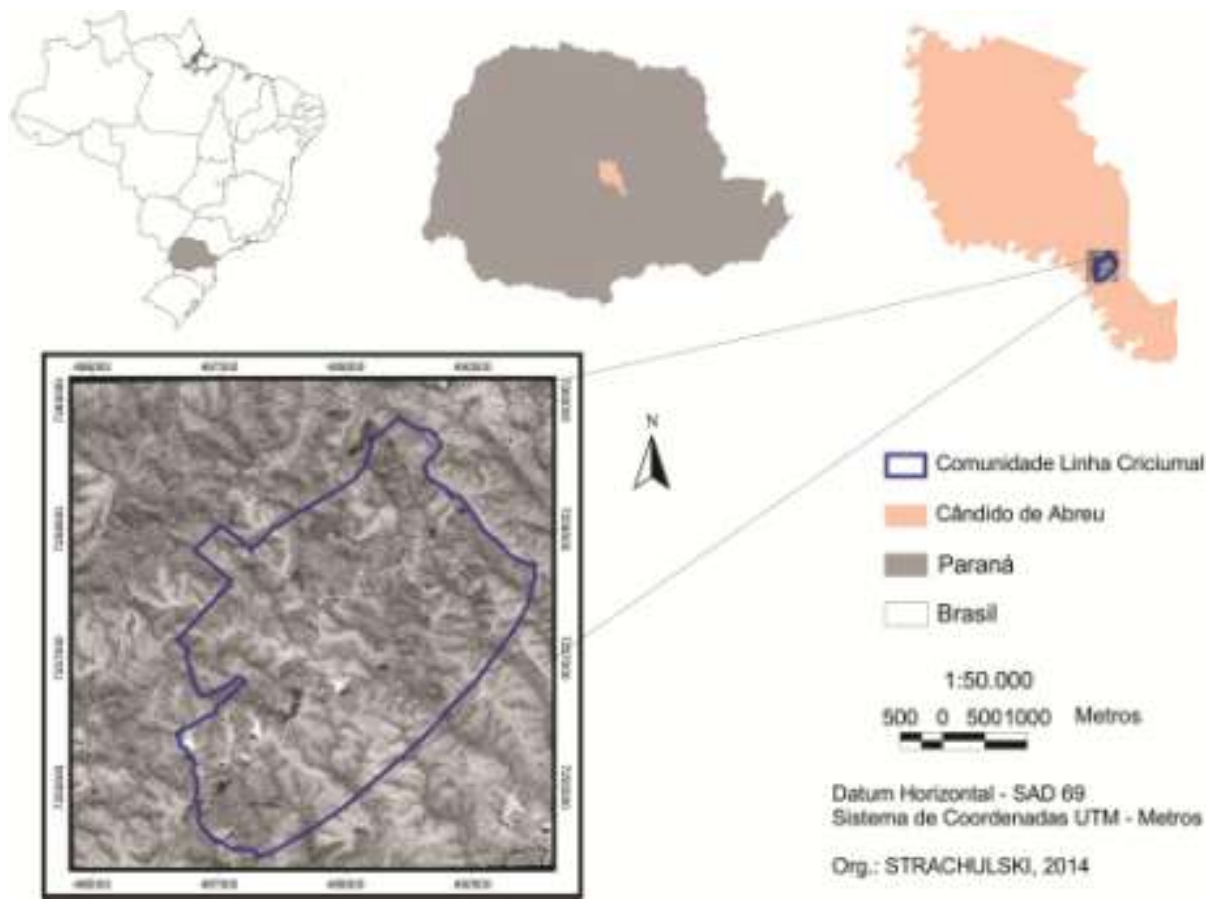

Fonte: O autor, 2014.

As características paisagísticas (Figura 3), apontadas para a região em que se insere a comunidade Linha Criciumal, presumem que haja uma relação de equilíbrio dinâmico entre as pessoas e o meio físico. De modo que, predomina o trabalho humano com auxílio de equipamentos tradicionais e de baixo impacto, resultando numa exploração pouco intensa dos recursos naturais, conferindo uma ligação harmônica entre o agricultor e a paisagem local.

Já a imagem que os moradores fazem da comunidade Linha Criciumal e a identidade deles nela expressa é aquela construída ao longo do tempo, não somente marcada por construções e características do meio físico, mas feita de ações, palavras e sentimentos.

Estes elementos estão expressos nas conversas cotidianas, quando as pessoas se encontram indo trabalhar ou quando uma visita à outra, como nos causos, nas opiniões e depoimentos acerca de processos observados, ouvidos ou percebidos. São lembranças que se propagam no tempo, graças à hereditariedade e que no embate com os processos atuais vão moldando a paisagem e identidade local, mas sem alterar por completo suas raízes, num processo constante e inacabado. 
Figura 3 - Vista parcial da paisagem da comunidade Linha Criciumal

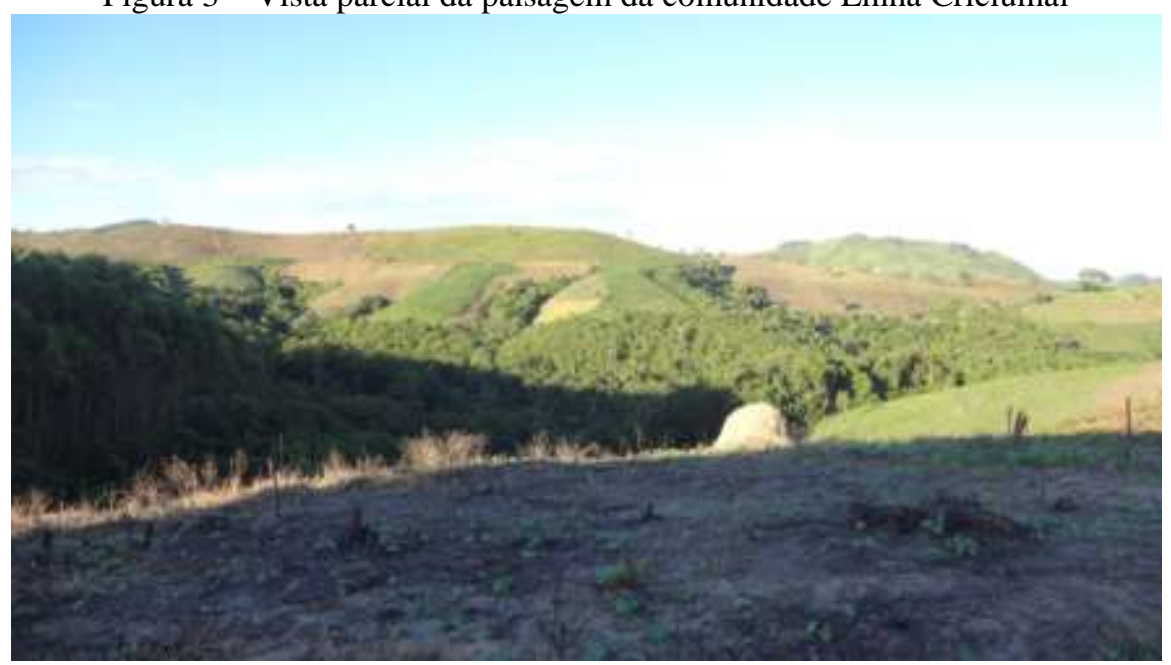

Fonte: $\mathrm{O}$ autor, 2014.

A paisagem de Linha Criciumal é vivenciada e imaginada por seus moradores a todo o momento, seja quando estão na área de lavoura, em suas casas ou circulando dentro da comunidade. Além de ser reflexo das ações empreendidas pelos moradores é moldada, inconscientemente, segundo suas concepções de mundo e características culturais.

A vivência dos moradores na comunidade, ao longo dos tempos, possibilitou que estabelecessem vínculos de ordem material e imaterial com esta paisagem, que apesar de estar sempre em processo de transformação não altera a ligação estabelecida. Isto é evidenciado quando se pergunta a uma jovem se gostaria de ir para uma cidade maior, e ela responde: "não, eu gosto daqui, de andar de cavalo, do cheiro do mato, caminhar pelo pasto".

A ligação das pessoas com a paisagem local, nestes termos, é expressa pelos geossímbolos que revelam as idéias, atitudes, estilos de vida, conhecimentos e muitos outros elementos da cultura local. Neste sentido, acabam estabelecendo com a paisagem por eles vivida um sentimento de pertencimento àquele lugar que é o lócus de sua origem e provavelmente o do fim de muitos.

Para Bonnemaison (2002, p. 124) este espaço de presença dos geossímbolos é "uma forma de linguagem, um instrumento de comunicação partilhado por todos e, em definitivo, o lugar onde se inscreve o conjunto da visão cultural”.

A paisagem apresentada e representada por seus geossímbolos enquanto um espaço cultural está carregada de "afetividade, de normas e limites sagrados, que dão suporte a uma identidade, coesão, apropriação física e postura" (GARZON, 2010, p. 20). Assim sendo, os 
geossímbolos locais denotam significados e representam características da cultura local, além de tornar visível a relação das pessoas com a sua paisagem.

Em Linha Criciumal persiste uma antiga paisagem matriz, cujas marcas em forma de geossímbolos permanecem até hoje. Como geossímbolos se pode destacar os paióis nas áreas de lavoura; os instrumentos agrícolas; os diques de diabásio; o terreiro, casa e paiol; o trajeto de procissão; o itinerário da santinha; a igreja; o crânio bovino; as encruzilhadas; dentre outros.

Os mais significativos geossímbolos são aqueles inerentes a prática agrícola, como os instrumentos de trabalho, que representam uma forma tradicional de fazer agricultura e demonstram uma relação de sintonia entre grupo humano e paisagem. Por outro lado, há os paióis e ferramentas (Figura 4A e B) localizados nas áreas de lavoura, que para os agricultores são concebidos enquanto uma segunda moradia. Pois aqueles que possuem áreas de lavoura distantes de suas residências passam a semana nestes, retornando ao seu final para a morada principal.

Figura 4 - Geossímbolos tradicionais inerentes a atividade agrícola na comunidade Linha Criciumal: A) paiol da área de lavoura, B) instrumentos agrícolas

A)

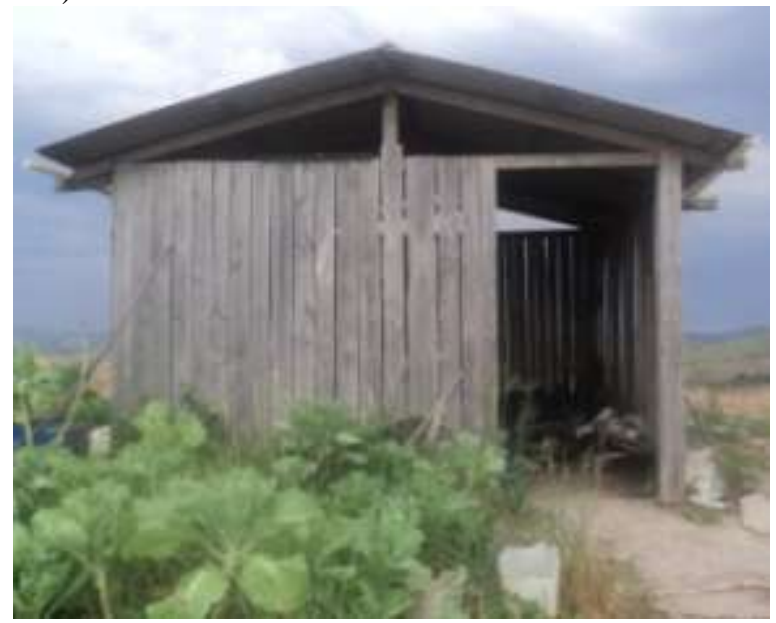

B)

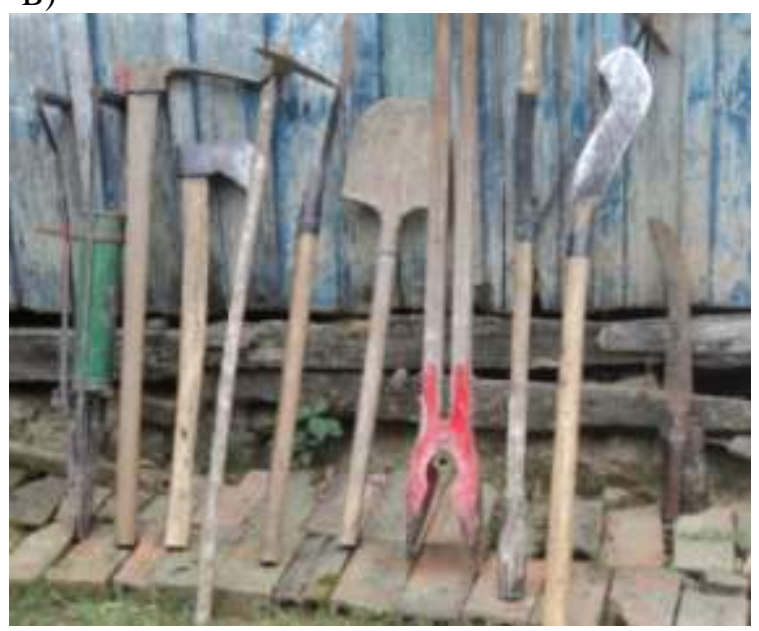

Fonte: $\mathrm{O}$ autor, 2012.

Outro elemento que pode ser considerado um geossímbolo estritamente ligado as práticas agrícolas é o dique de diabásio (Figura 5). Este é localmente denominado por "manga" ou "veia", considerado a representação material do que é uma terra boa, fértil, para a atividade agrícola, mostrando a importância do conhecimento local na identificação dos tipos de terras e suas qualidades. 


\begin{tabular}{|l|l|}
\hline & $\begin{array}{c}\text { GEOAMBIENTE ON-LINE } \\
\text { Revista Eletrônica do Curso de Geografia - UFG/REJ } \\
\text { Graduaçăo e Pós-Graduaçăo em Geografia } \\
\text { http://revistas.ufg.br/index.php/geoambiente/index } \\
\text { Apoio: PRPG/PROAPUPEC } \\
\text { Jataí-Go | n.24 | Jan-Jun/2015 }\end{array}$
\end{tabular}

Figura 5 - Geossímbolo que representa o que é uma terra boa para a atividade agrícola

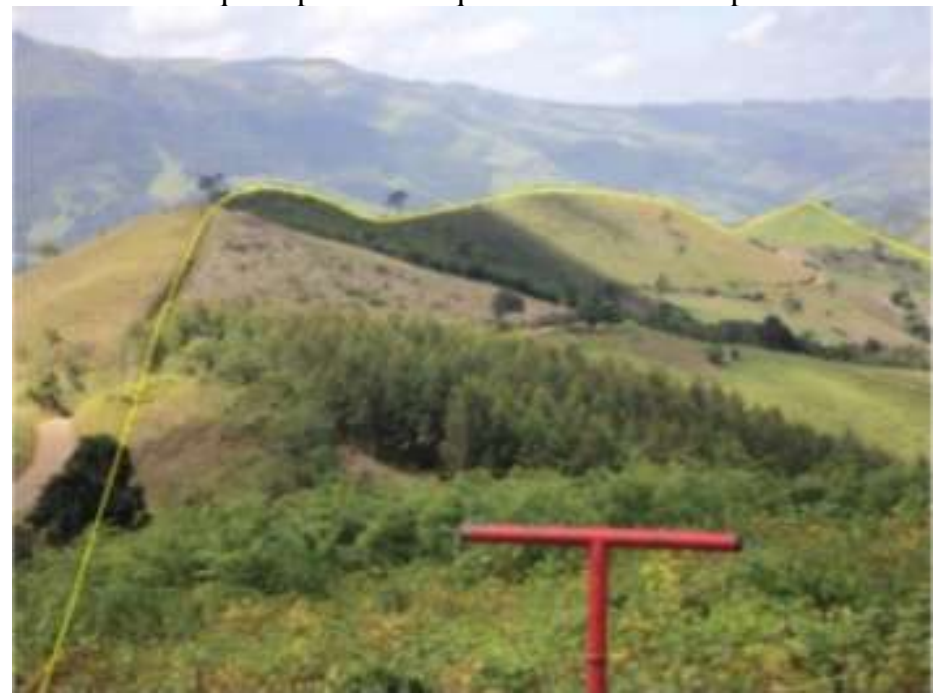

Fonte: O autor, 2013.

Desta forma, é possível constatar que a organização da paisagem esta condicionada pelos geossímbolos que dão vida e sentido a impressões, percepções e representações do cotidiano. Pois "a paisagem não é a simples adição de elementos geográficos disparatados" (BERTRAND, 1968 apud CLAVAL, 2002, p. 174). Ao contrário, é uma associação de vários elementos, tanto naturais, quanto antrópicos, que lhe conferem valor e sentido, a partir da instituição dos geossímbolos.

A paisagem e seus elementos representam mais do que a forma de vida das pessoas, eles representam o modo como as pessoas pensavam, como se relacionavam com a natureza ao seu redor, como compartilhavam informações, sendo possível que a partir da descrição e análise dos geossímbolos perceba-se a natureza trajetiva da paisagem (HOLZER, 2008).

Suas marcas persistem, como é o caso de um evidente padrão organizacional arquitetônico vernacular do tipo "casa-paiol” (Figura 6) em contiguidade com o terreiro e à mata que circunda a residência.

A casa, o terreiro e o paiol representam a relação do trabalho com o lazer, pois é no paiol que guardam o fruto de seu trabalho e a casa e o terreiro é onde desfrutam do resultado deste, sendo, portanto, relacionados a práticas produtivas e sociais. Tais geossímbolos definem, de acordo com Rua (2005, p. 55), “a inscrição da cultura de um grupo sobre seu espaço, enquanto produto de apropriação e valorização simbólica (afetiva)”. 




Figura 6 - Geossímbolo tradicional: casa, paiol e o terreiro

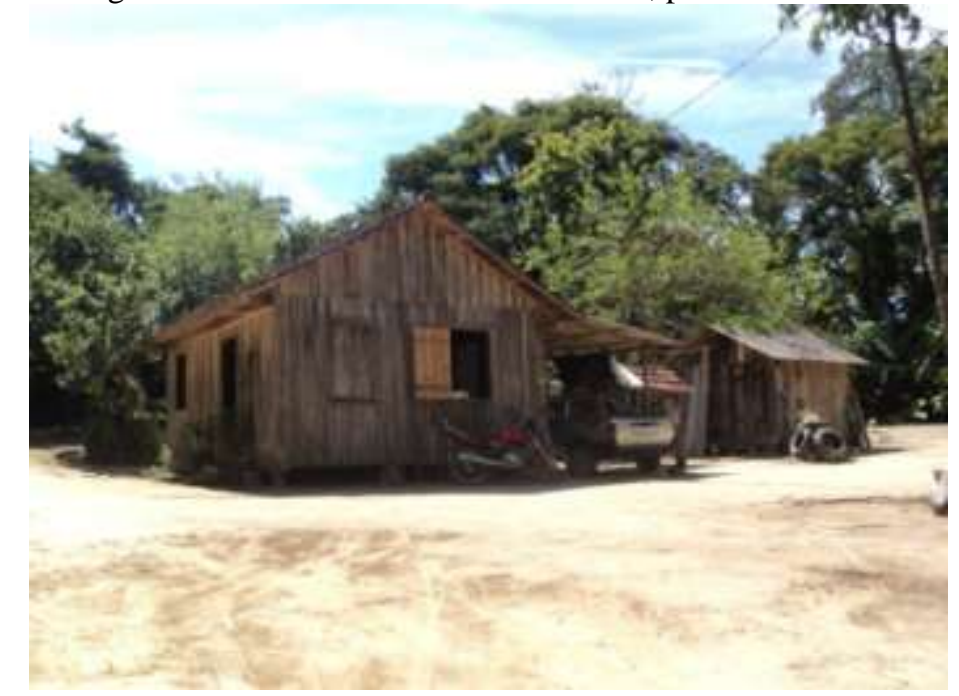

Fonte: O autor, 2013.

Os geossímbolos de uma paisagem representam referências para a memória de vários grupos humanos, pois reforçam as relações sociais e a identidade local, fortalecendo as representações do cotidiano (paisagem vivida). Assim, a cada momento vivido ajudam a reavivar a ligação dos indivíduos com a paisagem que os envolve.

Portanto, outro elemento ligado aos geossímbolos e a própria paisagem é a memória, que encontra naqueles "uma "âncora" significativa, compartilhada" (PANTOJA, 2011, p. 116), que possibilita uma construção coletiva de conhecimentos, lendas e narrativas acerca de determinada paisagem.

Estes geossímbolos estão repletos de recordações, fatos e histórias que reforçam algumas superstições locais como a crença na existência de ouro em locais onde aparece fogo à noite no meio da mata, no lobisomem e assombrações. Além disso, mostram a história destes agricultores que em tempos antigos levavam uma vida sofrida devido às adversidades do meio físico local, mas que também remontam a causos, que proporcionam risadas, incredulidade, apreensão e curiosidade.

Outro aspecto importante se refere à matriz religiosa, sendo que a maioria dos moradores são católicos (84\%), e a minoria evangélicos (16\%), enquanto a etnia declarada dominante é a polonesa, seguida da cabocla e ucraniana.

Em termos geossimbólicos (BERQUE, 1998; RUA, 2005), o domínio da religião católica se faz presente na paisagem da comunidade, quando da localização da igreja no centro da mesma, não havendo igrejas de base protestante (evangélicas), estando estas 


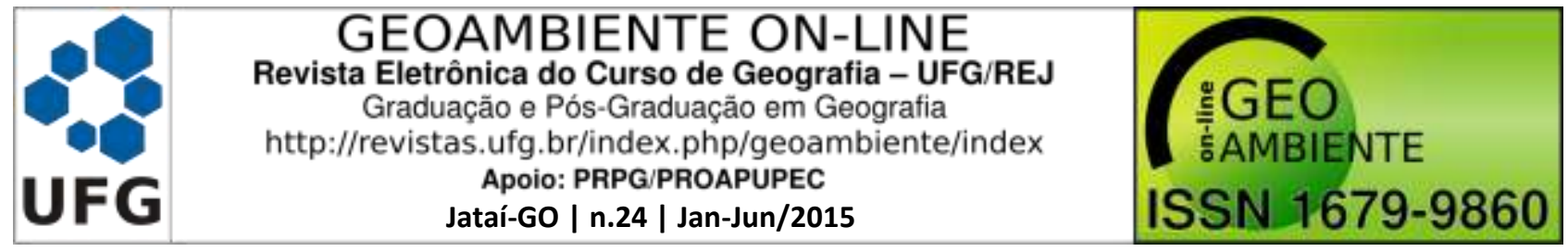

localizadas em comunidades vizinhas. Portanto, mediante os geossímbolos a religião de um grupo grava marcas que caracterizam e demarcam uma paisagem, território, ou lugar com características religiosas (ROSENDAHL, 2003).

A igreja, o que está em seu interior e em seus arredores são considerados lugares sagrados, mas também profanos e imbuídos de valores, o que lhes confere um conteúdo geossimbólico, pois ao longo dos tempos vem sendo palco de ressignificações de ocorrências sagradas e profanas (celebrações religiosas e festas).

Neste sentido, a paisagem que congrega estes geossímbolos se torna "uma estrutura visível, na qual a mensagem que nela se escreve em termos geossimbólicos reflete o peso do sonho, das crenças dos homens e de sua busca de significação" (ROSENDHAL, 2003, p. 215).

Ainda se referindo à religião, o caminho percorrido pelos fiéis católicos em suas procissões, como a da Sexta-Feira Santa (até a igreja) e o trajeto da "capelinha" (até as casas das pessoas) também podem ser compreendidos enquanto um geossímbolo, a partir do referencial de Bonnemaison (2002). O trajeto da procissão da Sexta-Feira Santa, para as pessoas da comunidade, está associado ao calvário de Jesus Cristo, relembrando o seu enterro e "sangue derramado" (Figura 7).

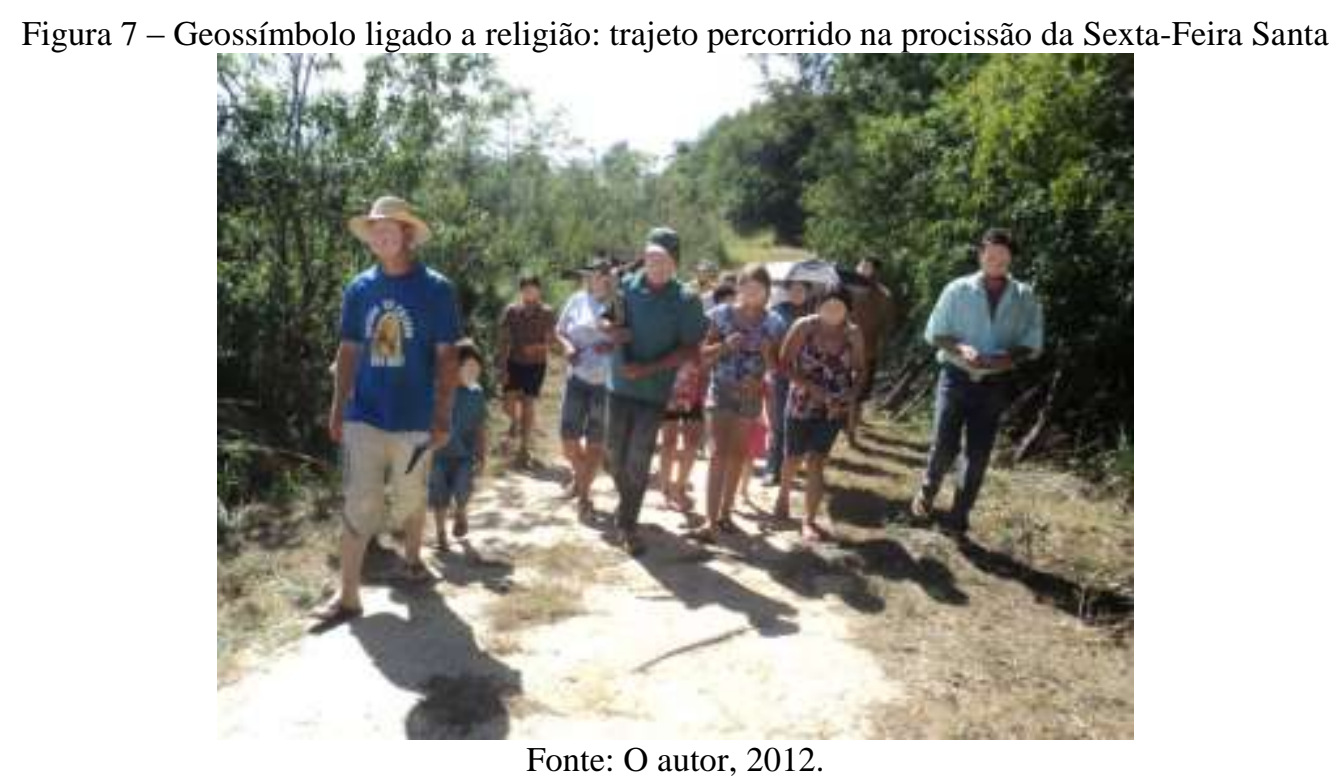

Já a visita da "santinha" (Figura 8) é um geossímbolo que está mais atrelado a reforçar os laços de união ente os membros católicos da comunidade e sua crença religiosa, pois percorre a casa de todos ao longo do ano. 


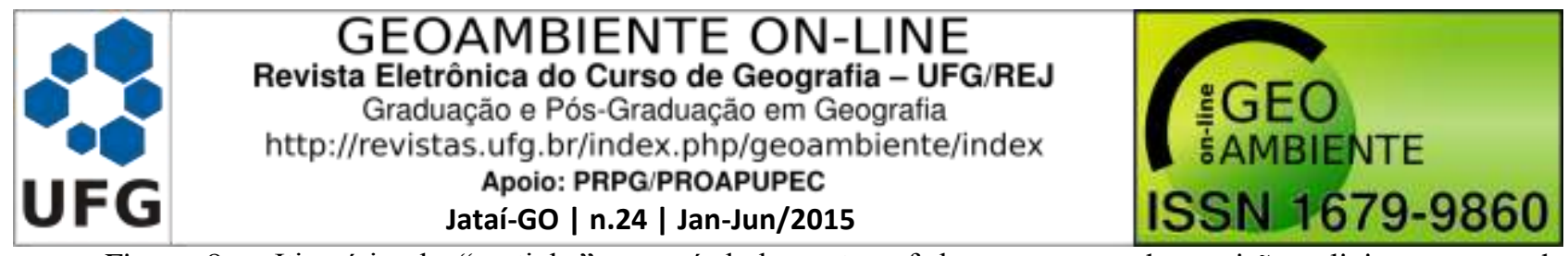

Figura 8 - Itinerário da "santinha": geossímbolo cartografado, representando a visão religiosa acerca da configuração da paisagem local

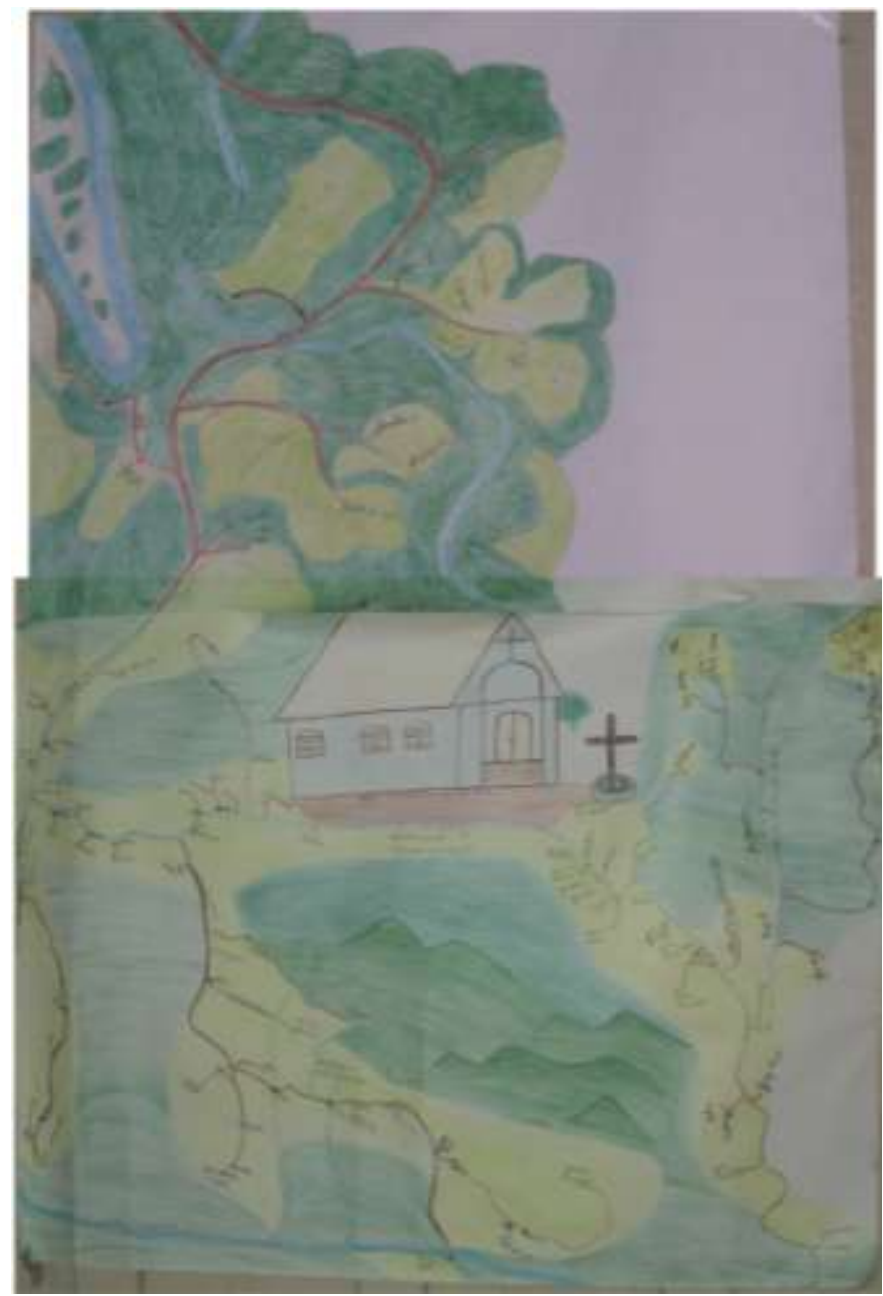

Fonte: O autor, 2012.

O itinerário da "santinha" foi inclusive objeto de representação pelas mulheres da religião católica, que por meio da cartografia vernacular expressam sua visão religiosa de como a paisagem da comunidade esta configurada. Cabe destacar que nesta visão a igreja é o elemento mais importante, encontrando-se ao centro do croqui e os elementos naturais como rios, relevo e vegetação adquirem conotação secundária.

A compreensão de que estes trajetos sejam geossímbolos é corroborada por Costa (2010, p. 41), visto que os elementos geossimbólicos relacionados à religião "são constituídos por templos, santuários, estátuas, colinas, fontes, lagos, roteiros devocionais, etc.”.

Outro geossímbolo que reflete as crenças e imaginário local é o crânio de gado bovino (Figura 9). Pois os moradores locais acreditam que este objeto trás proteção a propriedade e residência da família que a tem postada na entrada de seu sítio ou próxima a sua casa. 


\begin{tabular}{|l|l|}
\hline & $\begin{array}{c}\text { GEOAMBIENTE ON-LINE } \\
\text { Revista Eletrônica do Curso de Geografia - UFG/REJ } \\
\text { Graduaçăo e Pós-Graduaçăo em Geografia } \\
\text { http://revistas.ufg.br/index.php/geoambiente/index } \\
\text { Apoio: PRPG/PROAPUPEC } \\
\text { Jataí-Go | n.24 | Jan-Jun/2015 }\end{array}$
\end{tabular}

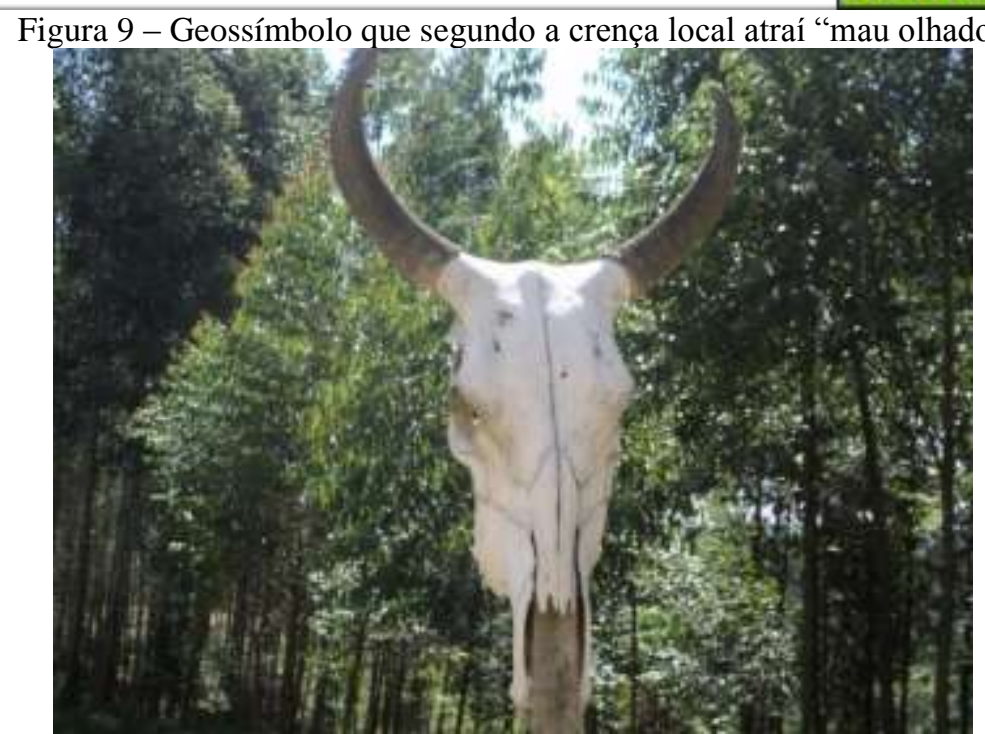

Fonte: $\mathrm{O}$ autor, 2012.

Acredita-se que tal objeto atrai o "mau olhado", os pensamentos negativos, impedindo que estes recaiam sobre seus animais, família e cultivos. Estes geossímbolos revelam uma paisagem que ressalta a importância das crenças para a vida das pessoas e manutenção da cultura local.

As "encruzilhadas" (Figura 10) também são geossímbolos locais associadas ao mundo mágico em que normalmente encontram-se espíritos, seres folclóricos, sendo também locais muito indicados pelos "pais de santo" para realizar trabalhos espirituais.

Figura 10 - Encruzilhada: geossímbolo local associado ao imaginário e cotidiano dos agricultores

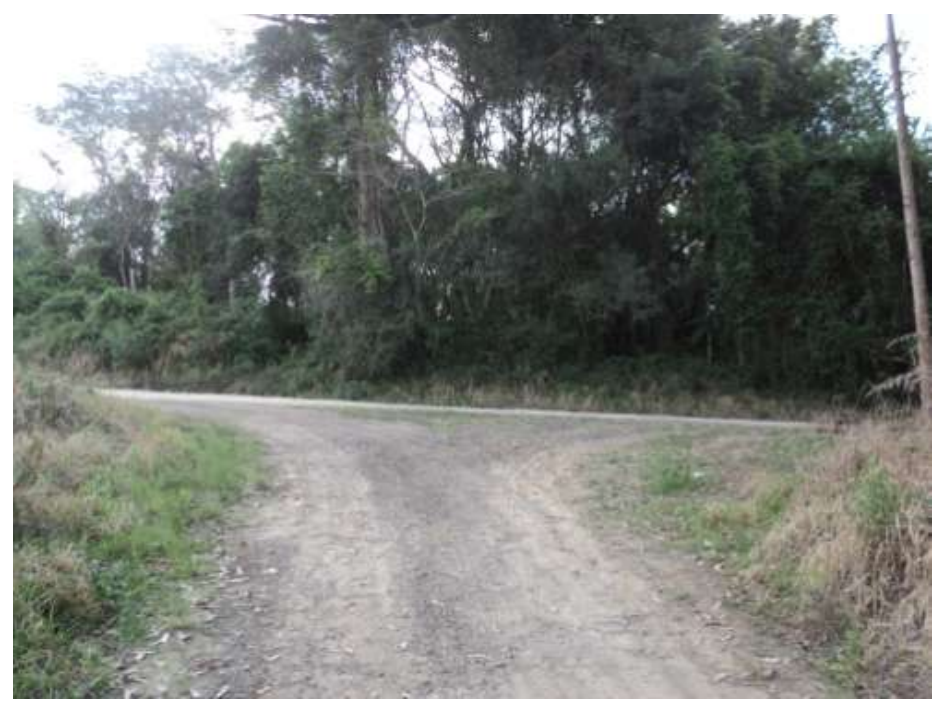

Fonte: O autor, 2013. 




Por outro lado, podem ser considerados como pontos de referência dentro da comunidade, pois geralmente utilizam o termo "encruzilhada" (lugar de encontro) para se localizar perante algo ou alguma paisagem (casa, mata, área de lavoura, pasto, outra comunidade, etc.). E como diz o significado do próprio termo, também representam paisagens de encontros entre os membros da comunidade que todo dia saem para trabalhar a caminho de suas áreas de lavoura.

A tipificação de comunidades rurais como Linha Criciumal se dá mediante os geossímbolos materializados na paisagem, identificados e caracterizados de forma a permitir fazer inferências com relação às práticas sociais, produtivas, religiosas e festivas nela expressas.

Portanto, esta ligação constituída entre os geossímbolos as paisagens e as pessoas está "carregada de afetividade e exprime uma relação cultural" (BONNEMAISON, 2002, p. 91), escrevendo a história de um povo com os elementos materiais de sua paisagem, que muitas vezes remetem ao imaginário.

\section{Considerações finais}

Buscou-se compreender a relação entre as pessoas a paisagem e os geossímbolos na comunidade rural Linha Criciumal em Cândido de Abreu - PR. Desta forma, verificou-se que há geossímbolos distintos, retratando as várias faces desta sociedade, como o trabalho agrícola, representado por seus vários instrumentos, construções e elementos do meio físico.

Também não se pode deixar de lado geossímbolos que destacam seu imaginário (crânio bovino, encruzilhadas, procissão, etc.), como aqueles inerentes a religião ou crenças, que retratam uma ligação das pessoas com a paisagem que revela o quanto as superstições interferem em suas vidas.

Tratando-se do meio rural, se torna importante ressaltar que este possui uma história muito rica e para que esta história continue existindo é de fundamental importância haver uma realidade materializada, ou seja, que haja geossímbolos presentes em sua paisagem. Pois, estes revelam elementos da cultura local estabelecidos pelas pessoas, além de ajudar a decifrar como estas se relacionam com sua paisagem.

Assim, os geossímbolos locais expressam as crenças, vivências e atitudes das pessoas frente à sua paisagem, que é moldada de acordo com suas necessidades. Tais registros 




mostram as marcas de uma sociedade sobre sua paisagem e a relação construída com esta ao longo do tempo.

Contudo, deve-se salientar que os geossímbolos somente representam algo para alguém que tenha uma longa convivência com a paisagem em que estavam inseridos e que tenham feito parte de algum momento importante de sua vida, tanto positivamente como negativamente.

Desta forma, alguns geossímbolos encontrados na comunidade Linha Criciumal podem ser mais importantes para algumas pessoas e menos importantes para outras. Por exemplo, para aqueles que não são agricultores, os instrumentos agrícolas e os paióis na área de lavoura têm pouca ou nenhuma importância. Aqueles geossímbolos que significam algo para as pessoas falam não somente da sua relação com a paisagem, mas também e principalmente, da relação das pessoas com a paisagem.

Os geossímbolos representam importantes elementos estruturantes da paisagem local, trazendo consigo sentimentos e valores e contando a história desta paisagem e das pessoas que com esta traçam seus caminhos.

Em termos gerais, se torna de suma importância compreender a relação dos geossímbolos com as paisagens, pois eles possibilitam captar a essência da relação das pessoas com o meio local. Além disso, possibilitam refletir as angústias, sonhos e pontos positivos de uma sociedade, reforçando e explicitando os sentimentos e crenças das pessoas acerca da paisagem vivida.

\section{Referências}

BONNEMAISON, J. Viagem em torno do território. In: CORRÊA, R. L.; ROSENDAHL, Z. (orgs.). Geografia cultural: um século (3). Rio de Janeiro: EdUERJ, 2002. p. 83-131.

BERQUE, A. Paisagem-marca, paisagem-matriz: elementos da problemática para uma geografia cultural. In: CORREA, R. L.; ROSENDAHL, Z. (Orgs.). Paisagem, tempo e cultura. 2. ed. Rio de Janeiro: EdUERJ, 1998. p. 84-91.

CLAVAL, P. A revolução pós-funcionalista e as concepções atuais da geografia. In: MENDONÇA, F.; KOZEL, S. (Orgs.). Elementos de epistemologia da geografia contemporânea. Curitiba: Editora da UFPR, 2002. p. 11-46.

CORRÊA, R. L. Formas simbólicas e espaço: algumas considerações. Aurora Geography Journal, v.1, 2007, p.11-19. 
CORREA, R. L. Região cultural: um tema fundamental. In:

(Orgs.) Espaço e cultura: pluralidade temática. Rio de Janeiro: EdUERJ, 2008, p. 11-43.

COSGROVE, D. A Geografia está em toda parte: cultura e simbolismo nas paisagens humanas. In: CORRÊA, R. L.; ROSENDAHL, Z. (Orgs.). Paisagem, tempo e cultura. Rio de Janeiro: EdUERJ, 1998, p. 92-123.

COSTA, O. J. L. Hierópolis: o significado dos lugares sagrados no sertão cearense. In: ROSENDAHL, Zeny. (Org.). Trilhas do sagrado. Rio de Janeiro: EdUERJ, 2010, p. 35-60.

DELGADO, C. C. Pensar el paisaje. Explorando un concepto geográfico. Trayectorias, v. 7, n. 17, enero-abril, 2005, p. 57-69. Disponível em: <http://www.redalyc.org/pdf/607/60722197007.pdf $>$. Acesso em: 20/01/2015.

ELIADE, M. Imagens e símbolos: ensaio sobre o simbolismo mágico-religioso. São Paulo: Martins Fontes, 1991.

GARZON, C. P. M. Análisis geoecológico en el altiplano occidental: paisajes naturales y culturales de la Cuenca Alta del Río Samalá. Guatemala: CONCYT/SENACYT/FONACYT/CEDEPEM S.C, 2010, p. 109.

GIL, A. C. Métodos e Técnicas de Pesquisa Social. 6. ed. São Paulo: Atlas, 2008.

GIMÉNEZ, G.; LAMBERT, C. H. El desierto como territorio, paisaje y referente de identidad. Culturales, v. 3, n. 5, enero-junio. 2007, p. 7-42. Disponível em: $<$ http://www.redalyc.org/articulo.oa?id=69430502 >. Acesso em: 25/01/2015.

HOLZER, W. A Trajeção: reflexões teóricas sobre a paisagem vernacular. In: ROSENDAHL, Z.; CORRÊA, R. L. (Orgs.). Espaço e cultura: pluralidade temática. Rio de Janeiro: Ed UERJ, 2008.

MEINIG, D. W. The interpretation of ordinary landscapes - Geographical essays. Oxford: University Press, 1979.

PANTOJA, W. W. R. Território e identidade: a experiência mórmon em Belém do Pará. 2011. 130 f. Dissertação (Mestrado em Geografia) - Universidade Federal do Pará, Belém, 2011. Disponível em: 〈http://www3.ufpa.br/ppgeo/Wallace\%20Pantoja.pdf>. Acesso em: $10 / 02 / 2015$.

ROSENDHAL, Z. Espaço, Cultura e Religião: Dimensões de Análise. In: CORRÊA, R. L.; ROSENDHAL, Z. (Orgs.). Introdução à Geografia Cultural. Rio de Janeiro: Bertrand Brasil, 2003, p. 187-224. 


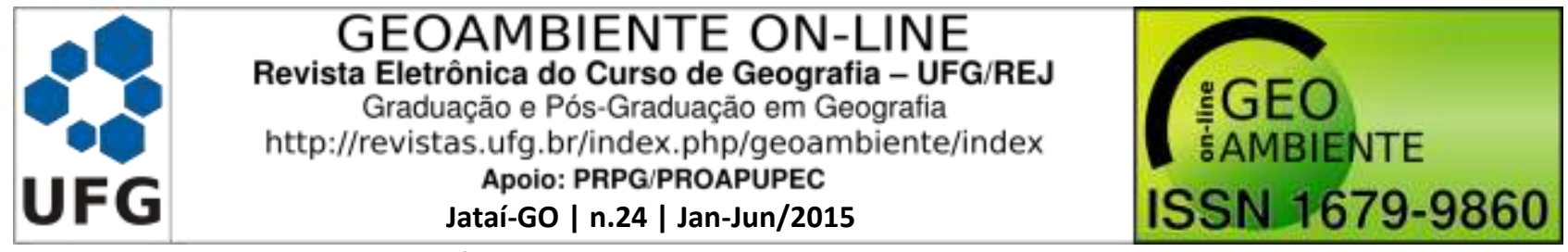

RUA, J. "A resignificação do rural e as relações cidade-campo: uma contribuição geográfica". Revista da Anpege, v. 2, n. 2, p. 45-65, 2005. Disponível em: 〈http://www.anpege.org.br/downloads/revista2/resignificacao.pdf >. Acesso em: 8/72/2012 SILVA, E. J.; TULUX, B. M.; LE BOURLEGAT, C. A. Educação e Preservação Patrimonial/Arqueológica no Desenvolvimento Territorial de Mato Grosso do Sul. Revista Impulso, v. 21, n. 51, jan-jun. 2011, p. 19-30. Disponível em: <https://www.metodista.br/revistas/revistasunimep/index.php/impulso/article/viewFile/378/54 6)>. Acesso em: 20/02/2015.

TEIXEIRA, J. P. Paisagens e territórios religiosos afro-brasileiros no espaço urbano: terreiros de candomblé em Goiânia. 2009. 140 f. Dissertação (Mestrado em Geografia) Universidade Federal de Goiás, Goiânia, 2009. Disponível em: $<$ http://repositorio.bc.ufg.br/tede/handle/tde/1903 >. Acesso em: 10/02/2015. 